\title{
Thresholds of whole-blood $\beta$-hydroxybutyrate and glucose concentrations measured with an electronic hand-held device to identify ovine hyperketonemia
}

\author{
M. Pichler, ${ }^{\star}$ A. Damberger, ${ }^{\star}$ I. Schwendenwein,† J. Gasteiner,‡ M. Drillich, ${ }^{*}$ and M. Iwersen ${ }^{\star 1}$ \\ ${ }^{*}$ Clinical Unit for Herd Health Management for Ruminants, University Clinic for Ruminants, Department for Farm Animals \\ and Veterinary Public Health, University of Veterinary Medicine Vienna, 1210 Vienna, Austria \\ †Central Clinical Pathology Unit, Department for Pathobiology, University of Veterinary Medicine Vienna, 1210 Vienna, Austria \\ $\ddagger$ Agricultural Research and Education Center Raumberg-Gumpenstein, 8952 Irdning (Styria), Austria
}

\begin{abstract}
Metabolic disorders, especially hyperketonemia, are very common in dairy sheep. The whole-blood concentrations of $\beta$-hydroxybutyrate (BHBA) and glucose can be determined by commercially available electronic hand-held devices, which are used in human medicine and for the detection of ketosis in dairy cows. The aim of this study was to evaluate the suitability of the hand-held device Precision Xceed (PX; Abbott Diabetes Care Inc., Abbott Park, IL) to detect hyperketonemia in ewes. An additional objective of this study was to evaluate the agreement between samples obtained by minimal invasive venipuncture of an ear vein and measurements of whole-blood samples from the jugular vein (vena jugularis, v. jug.). Blood samples taken from the v. jug. were collected from 358 ewes on 4 different farms. These samples and a blood drop obtained from an ear vein were analyzed simultaneously on farm with the PX. For method comparison, the samples obtained from the v. jug. were also analyzed by standard methods, which served as the gold standard at the Central Laboratory of the University of Veterinary Medicine Vienna, Austria. The correlation coefficients between the serum BHBA concentration and the concentrations measured with the hand-held meter in the whole blood from an ear vein and the v. jug. were 0.94 and 0.96 , respectively. The correlation coefficients of plasma and whole-blood glucose concentration were 0.68 for the v. jug. and 0.47 for the ear vein. The mean glucose concentration was significantly lower in animals classified as hyperketonemic (BHBA $\geq 1.6 \mathrm{mmol} / \mathrm{L})$ compared with healthy ewes. Whole-blood concentrations of BHBA and glucose measured with the PX from v. jug. showed a constant negative bias of $0.15 \mathrm{mmol} / \mathrm{L}$ and $8.4 \mathrm{mg} /$ $\mathrm{dL}$, respectively. Hence, a receiver operating characteristic analysis was performed to determine thresholds for
\end{abstract}

Received June 21, 2013.

Accepted November 16, 2013.

${ }^{1}$ Corresponding author: Michael.Iwersen@vetmeduni.ac.at the PX to detect hyperketonemia in ewes. This resulted in thresholds for moderate ketosis of BHBA concentrations of $0.7 \mathrm{mmol} / \mathrm{L}$ in blood from an ear vein and the $\mathrm{v}$. jug. Cutoffs of $1.0 \mathrm{mmol} / \mathrm{L}$ (ear vein) and $1.1 \mathrm{mmol} / \mathrm{L}$ (v. jug.) BHBA were determined to detect animals at greater risk to develop severe hyperketonemia. Applying these thresholds, excellent test characteristics, with sensitivities of 1.00 for both samples and specificities of 0.98 for the ear vein and 0.97 for the v. jug. were determined. These results demonstrate that the PX is a useful tool for detection of hyperketonemia in ewes.

Key words: pregnancy toxemia, ketosis, hand-held meter, $\beta$-hydroxybutyrate

\section{INTRODUCTION}

Pregnancy toxemia (hyperketonemia, twin-lamb disease, or ketosis) is one of the most common metabolic disorders in pregnant small ruminants, which leads often to a herd or flock problem (Rook, 2000; Mavrogianni and Brozos, 2008). Mortality rates up to $80 \%$ are common in affected animals (Rook, 2000). Whereas in cattle and milk goats, ketosis usually manifests within the first weeks after parturition, in ewes, $75 \%$ of all cases of this affliction occur before lambing (Bostedt and Dedie, 1996). Predisposed animals are undernourished dams, especially during the last trimester of gestation, but also ewes in very good body condition (Liamadis and Milis, 2007). Ewes carrying multiple fetuses and meat breeds are at greater risk to develop this metabolic disorder (Henze et al., 1998; Schlumbohm and Harmeyer, 2004, 2008; Moallem et al., 2012). An increased concentration of BHBA is diagnostic for the disease (Henze et al., 1998; Mavrogianni and Brozos, 2008; Bickhardt, 2009). In contrast to dairy cows, an increased concentration of ketone bodies is not always accompanied by a lack of glucose in ewes (Andrews, 1997; Rook, 2000). Whereas in severe cases of ketosis, affected ewes show clinical signs of disease (e.g., recumbency and coma) that can be recognized easily, detect- 
ing cases of moderate ketosis is more challenging. This can be achieved by analysis of blood samples. Moderate ketosis is defined as serum BHBA concentration between 0.8 and $1.6 \mathrm{mmol} / \mathrm{L}$ (Andrews, 1997; Rook, 2000; Sargison, 2007). The threshold to distinguish between moderate ketosis and ewes at greater risk to develop clinical ketosis (= severe hyperketonemia) is defined as a BHBA concentration $\geq 1.6 \mathrm{mmol} / \mathrm{L}$ (Andrews, 1997; Bickhardt, 2009). Physiological plasma glucose concentrations range between 31 to $80 \mathrm{mg} / \mathrm{dL}$ (Andrews, 1997; Christian and Pugh, 2012). The efficacy of the treatment of ketosis depends on an immediate therapy, which relies on timely and correct diagnosis of the disease. Even in cases of early initiation of treatment, however, this may still fail (Brozos et al., 2011). Using an on-site test to detect hyperketonemia in ewes would allow a targeted treatment without shipping samples to a laboratory. For use in cattle, some electronic devices have already been evaluated and were rated as useful and practical tools to diagnose subclinical ketosis (Oetzel and McGuirk, 2007; Iwersen et al., 2009; Voyvoda and Erdogan, 2010). For ovine on-site testing for ketosis Panousis et al. (2012) reported a significant positive correlation between glucose $(\mathrm{r}=0.76)$ and BHBA $(\mathrm{r}=$ 0.99 ) concentrations analyzed in a laboratory and with the hand-held meter Precision Xceed (PX; Abbott Diabetes Care Inc., Abbott Park, IL). They determined a high sensitivity (Se) and specificity $(\mathbf{S p})$ for detection of moderate ketosis based on laboratory results. This study from Greece was conducted with 1 breed of dairy sheep.

The objective of the present study was to evaluate the electronic hand-held meter PX for diagnosis of moderate and severe hyperketonemia in ewes. A systematic assessment of the hand-held meter in combination with the evaluation of 2 established thresholds (BHBA $\geq 0.8$ $\mathrm{mmol} / \mathrm{L}$ or $\geq 1.6 \mathrm{mmol} / \mathrm{L}$ ) should demonstrate the accuracy of this test system. An additional objective was to evaluate the agreement between measurement of BHBA and glucose in a single blood drop obtained by minimal invasive venipuncture of an ear vein and the concentration in the sample taken from the vena jugularis (v. jug.).

\section{MATERIALS AND METHODS}

\section{Animals}

This study was conducted with 358 ewes from different breeds: Tyrol Mountain $(\mathrm{n}=112)$, East Friesian milk sheep $(\mathrm{n}=90)$, Merino $(\mathrm{n}=77)$, Tyrol Steinschaf $(\mathrm{n}=41)$, Tyrol Mountain crossbred with Merino $(\mathrm{n}=20)$, and Brown Tyrol Mountain $(\mathrm{n}=18)$. Animals were provided by the Teaching and Research
Farm Kremesberg (University of Veterinary Medicine Vienna, Austria; $\mathrm{n}=155$ ), the Agricultural Research and Education Center Raumberg-Gumpenstein (Styria, Austria; $\mathrm{n}=88$ ), and 2 commercial sheep farms (farm $1, \mathrm{n}=90$; farm $2, \mathrm{n}=25$ ) in Austria. The age of the ewes ranged between 18 mo and 7 yr. All ewes were kept in groups on deep litter. A few days before lambing up to 1 wk after parturition ewes were kept separated in single boxes but with contact to the herd.

The sampling periods were between January and May 2011, and between September 2011 and May 2012, according to the lambing season. Sampling was performed from nonlactating pregnant animals within the last trimester of pregnancy (pregnant, $\mathrm{n}=160$ ) as well as from nonpregnant ewes within early and mid lactation (lactating, $\mathrm{n}=198$ ).

The study was approved by the institutional ethics committee and the national authority (BMWF68.205/0061-II/3b/2011) and by the Federal State Styria (FA10A-78Gu-15/2011-2) according to $\S 8 f f$ of the Law for Animal Experiments.

\section{Sampling}

Animals were restrained manually and checked visually for any health disorders before sampling. After cleaning and disinfection with ethanol of one of the ears, an ear vein was chosen by size and visibility for venipuncture (Erosa Injektionskanüle, $1.2 \times 50 \mathrm{~mm}$; Rose GmbH, Trier, Germany). The obtained blood drop (at least $0.60 \mu \mathrm{L}$ ) was analyzed with the electronic hand-held meter PX to determine the whole-blood concentration of BHBA and glucose using the test strips Precision Xtra Plus $\beta$-ketone strips and Precision Xtra Plus glucose strips (Abbott Diabetes Care Inc.), respectively, according to the manufacturer's instructions.

Additionally, 2 blood samples were collected from the v. jug., using a blood-collection tube system (Vacuette; Greiner Bio-One GmbH, Kremsmünster, Austria) and a 20-gauge needle (Vacuette $0.9 \times 38 \mathrm{~mm}$; Greiner Bio-One GmbH). For determination of BHBA concentration, a serum tube coated with microscopic silica particles (Vacuette, Z-Serum Clot Activator; Greiner Bio-One GmbH) was used. To evaluate the concentration of glucose, a tube with sodium fluoride/potassium additive oxalate was chosen (Vacuette; Greiner Bio-One $\mathrm{GmbH}$ ). Both samples were analyzed immediately after collection with the PX and the appropriate test stripes for determination of BHBA and glucose. After blood application, whole-blood BHBA (mmol/L) and glucose $(\mathrm{mg} / \mathrm{dL})$ concentrations were presented at the display of the electronic device after 10 and $5 \mathrm{~s}$, respectively.

After approximately $2 \mathrm{~h}$ of clotting, serum tubes were centrifuged (Eppendorf Centrifuge 5804; Eppendorf 
AG, Hamburg, Germany) at 2,200 $\times g$ for $10 \mathrm{~min}$ at room temperature and tubes with sodium fluoride/potassium additive oxalate were centrifuged at 2,200 $\times g$ for $5 \mathrm{~min}$ at room temperature. Serum and plasma was stored in 2 aliquots each in Twist Top Vials $(2.0 \mathrm{~mL}$; Carl Roth GmbH \& Co. KG, Karlsruhe, Germany) at $-25^{\circ} \mathrm{C}$ until analysis at the Central Clinical Pathology Unit (CCPU) at the University of Veterinary Medicine Vienna, Austria (Vetmeduni Vienna). The BHBA and glucose concentrations determined in serum or plasma at the CCPU were defined as the gold standard.

\section{Laboratory Proceedings}

Concentrations of BHBA and glucose were analyzed at the CCPU using a fully selective autoanalyzer for clinical chemistry (Cobas 6000/c501; Roche Diagnostics GmbH, Vienna, Austria). For BHBA measurement, a colorimetric enzymatic method (RANBUT, D-3-hydroxybutyrate; Randox Laboratories Ltd., Crumlin, UK) was used. The enzyme 3-hydroxybutyrate-dehydrogenase causes an oxidation of D-hydroxybutyrate with $\mathrm{NAD}^{+}$to acetoacetate with the concomitant $\mathrm{NAD}^{+}$reduction of NADH. The reduction of the $\mathrm{NAD}^{+}$ leads to a change in color, which is proportional to the concentration of BHBA.

The concentration of glucose was determined by an enzymatic colorimetric reaction. Glucose and ATP are metabolized by hexokinase to glucose-6-phosphate and adenosine diphosphate (ADP). The mean product of this reaction is NADPH. The turnover rate leads to a color change, which is proportional to glucose concentration.

\section{Statistical Analysis}

Data were analyzed using PASW statistical software (PASW Statistics 17, 2010; IBM Deutschland GmbH, Ehningen, Germany) and BiAS software (version 9.07; Epsilon-Verlag, Darmstadt, Germany). The Pearson correlation coefficients were calculated for concentrations of BHBA and glucose in the gold standard and determined by the hand-held device in a blood drop of an ear vein and in whole blood from the v. jug. The level of significance for all statistical tests was set at $P$ $<0.05$.

Based on serum BHBA concentrations, ewes were classified as physiologically $(<0.8 \mathrm{mmol} / \mathrm{L})$, moderately $(0.8-1.5 \mathrm{mmol} / \mathrm{L})$, or severely $(\geq 1.6 \mathrm{mmol} / \mathrm{L})$ ketotic animals. Applying the established BHBA thresholds of 0.8 and $1.6 \mathrm{mmol} / \mathrm{L}$, test characteristics $\mathrm{Se}, \mathrm{Sp}$, and the Youden index (YI) were calculated for the electronic device. Sensitivity was defined as the ability to identify an animal with a moderate BHBA concentration in blood $\geq 0.8 \mathrm{mmol} / \mathrm{L}$ or a severe hyperketonemic ewe with a BHBA concentration $\geq 1.6 \mathrm{mmol} / \mathrm{L}$. Specificity was defined as the ability to identify healthy ewes with a BHBA concentration $<0.8 \mathrm{mmol} / \mathrm{L}$. By using receiver operating characteristic (ROC) analyses, optimized thresholds for the PX hand-held meter were determined to detect animals suffering from moderate and severe ketosis, and to classify ewes as hypo- or hyperglycemic. The area under the ROC curve demonstrates the efficiency of the diagnostic test system. The YI was evaluated to assess the quality of the test system. This index is frequently used as summary measure of the ROC curve and is calculated according to Se and Sp (Fluss et al., 2005). According to the glucose thresholds used by the CCPU (Schwendenwein, 2009), the results were classified as hypoglycemic $(<49 \mathrm{mg}$ / $\mathrm{dL}$ ), normoglycemic $(50-63 \mathrm{mg} / \mathrm{dL})$, or hyperglycemic $(>63 \mathrm{mg} / \mathrm{dL}$ ).

The Bland-Altman plot of difference against mean allows assessment of any possible relationship between the measurement error of the electronic device and the gold standard (Bland and Altman, 1986). Means, standard deviation, and binomial $95 \%$ confidence intervals $\left(\mathbf{C I}_{\mathbf{9 5}}\right)$ for the plot were calculated. To report any significant difference of BHBA concentration stratified by reproductive status (pregnant vs. lactating) within each individual breed and farm, a Mann-Whitney test was used. Spearman correlation was calculated to show if a correlation $(P<0.05)$ existed between BHBA and glucose concentrations. A one-way ANOVA and Bonferroni post hoc test were used to determine differences between the BHBA and glucose concentrations in the classes.

\section{RESULTS}

\section{Concentration of BHBA}

In total, blood samples were collected from 358 sheep; $44.7 \%(\mathrm{n}=160)$ of all samples were collected from pregnant ewes 21 to $1 \mathrm{~d}$ before parturition; $55.3 \%$ ( $\mathrm{n}=$ 198) of the samples were collected from lactating ewes between 0 to $69 \mathrm{~d}$ after lambing. The samples from the v. jug. were analyzed in the CCPU and with the PX hand-held meter. The descriptive statistics of the BHBA and glucose concentrations stratified for breeds and study sites are presented in Tables 1 and 2. The breed of East Friesian milk sheep showed the greatest percentages in moderate $(24.4 \%)$ and severe $(15.6 \%)$ hyperketonemia. In $65.9 \%$ of the Tyrol Steinschaf breed and $65.0 \%$ of the Tyrol Mountain crossbreeds, glucose concentrations $\geq 64 \mathrm{mg} / \mathrm{dL}$ were found, which are defined as hyperglycemic (Table 1). Because all milk sheep were kept on farm 1, the reported percentages 
Table 1. Descriptive statistics of laboratory BHBA and glucose concentration stratified for the different breeds (animals: $\mathrm{n}=358$ )

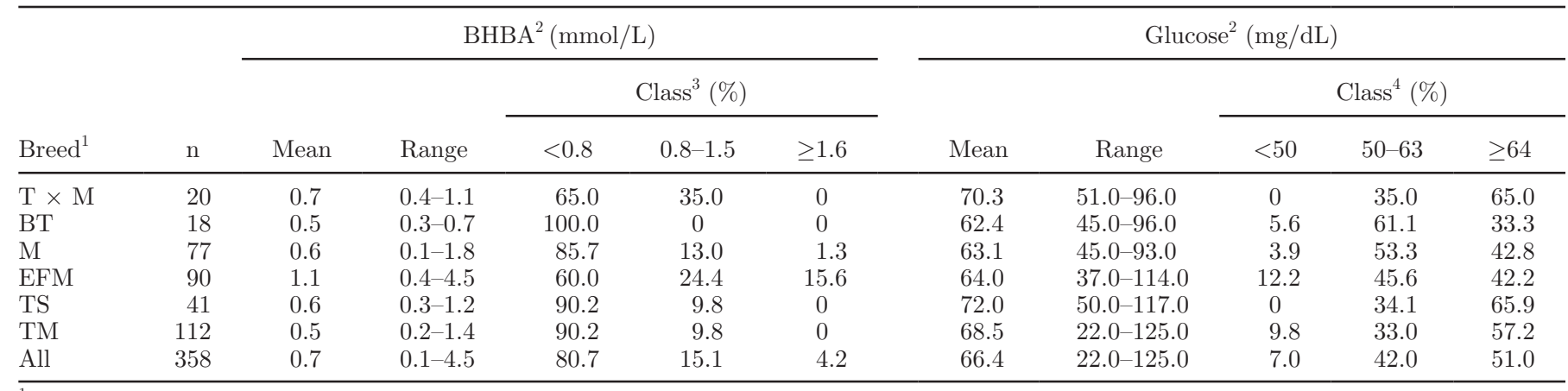

${ }^{1} \mathrm{~T} \times \mathrm{M}=$ Tyrol Mountain $\times$ Merino crossbreed; BT $=$ Brown Tyrol Mountain; $\mathrm{M}=$ Merino; EFM $=$ East Friesian milk sheep; TS $=$ Tyrol Steinschaf; TM = Tyrol Mountain; All = all breeds in total.

${ }^{2}$ Serum BHBA and plasma glucose concentration measured in laboratory = gold standard.

${ }^{3}$ Percentages of ewes with physiological, moderate, and severe BHBA concentrations $(\mathrm{mmol} / \mathrm{L})$.

${ }^{4}$ Percentages of ewes with hypo-, normo-, and hyperglycemic glucose concentrations $(\mathrm{mg} / \mathrm{dL})$.

for this farm (Table 2) are equal to the results for milk sheep in Table 1. Table 3 shows the BHBA concentrations for the ewes, considering their reproductive status and different BHBA classes. The serum BHBA concentrations of all samples analyzed at the CCPU ranged from 0.1 to $4.5 \mathrm{mmol} / \mathrm{L}$. The mean BHBA concentrations determined with the PX in a blood drop from an ear vein were $0.6 \pm 0.5 \mathrm{mmol} / \mathrm{L}(0.1$ to $3.6 \mathrm{mmol} / \mathrm{L}$ ) and $0.5 \pm 0.5 \mathrm{mmol} / \mathrm{L}(0.1$ to $3.4 \mathrm{mmol} / \mathrm{L})$ measured in whole blood of the v. jug. In total, $80.7 \%(\mathrm{n}=289)$ of all samples were found with BHBA concentrations below $0.8 \mathrm{mmol} / \mathrm{L}$ (physiological), $15.1 \%(\mathrm{n}=54)$ ranged between 0.8 and $1.6 \mathrm{mmol} / \mathrm{L}$ and were classified as moderately ketonemic, and $4.2 \%(\mathrm{n}=15)$ were above the BHBA threshold of $1.6 \mathrm{mmol} / \mathrm{L}$, indicating animals at greater risk to develop severe ketosis (Table 3). Clinical symptoms in combination with BHBA concentrations $\geq 1.6 \mathrm{mmol} / \mathrm{L}$ were diagnosed in 9 ewes. Recumbency was found in 5 ewes, which were all pregnant. One of these ewes with the greatest BHBA concentration $(4.5 \mathrm{mmol} / \mathrm{L})$ showed a combination of clinical symptoms of pregnancy toxemia (recumbency, anorexia, and depression) and died. A pathological section was performed and fatty liver was diagnosed. Additionally, reduced appetite and moderate depression of behavior was found in 4 animals (pregnant: $\mathrm{n}$ $=3$; lactating: $\mathrm{n}=1$ ), but 1 of them was suffering from clinical mastitis, too. Overall, no significant difference in the BHBA concentrations was found between pregnant and lactating ewes, but stratified for different breeds, the BHBA concentrations were significantly greater in pregnant milk sheep and Merino sheep compared with lactating ewes of the same breed $(P<0.05)$. The Pearson correlation coefficients between the serum BHBA concentration and the whole-blood BHBA levels measured with the PX in the samples taken from an ear vein and from the v. jug. were 0.94 and 0.96 (both $P<$ 0.01 ), respectively.

Bland-Altman plots for samples collected from an ear vein showed a mean difference in serum (CCPU) and whole-blood (hand-held device) BHBA concentration of $0.13 \mathrm{mmol} / \mathrm{L}\left(\mathrm{CI}_{95}=-0.22\right.$ to 0.48 ; Figure

Table 2. Descriptive statistics of laboratory BHBA and glucose concentration stratified for the different farms from 358 ewes

\begin{tabular}{|c|c|c|c|c|c|c|c|c|c|c|c|}
\hline Farm & $\mathrm{n}$ & \multicolumn{5}{|c|}{$\operatorname{BHBA}^{1}(\mathrm{mmol} / \mathrm{L})$} & \multicolumn{5}{|c|}{ Glucose $^{1}(\mathrm{mg} / \mathrm{dL})$} \\
\hline 1 & 90 & 1.1 & $0.4-4.5$ & 60.0 & 24.4 & 15.6 & 64.0 & $37.0-114.0$ & 12.2 & 45.6 & 42.2 \\
\hline 2 & 88 & 0.5 & $0.2-1.1$ & 88.6 & 11.4 & 0 & 64.6 & $22.0-125.0$ & 8.0 & 47.7 & 44.3 \\
\hline 3 & 155 & 0.5 & $0.1-1.4$ & 92.3 & 7.7 & 0 & 68.9 & $41.0-117.0$ & 4.5 & 38.1 & 57.4 \\
\hline
\end{tabular}

${ }^{1}$ Serum BHBA and plasma glucose concentration measured in laboratory = gold standard.

${ }^{2}$ Percentages of ewes with physiological, moderate, and severe BHBA concentrations (mmol/L).

${ }^{3}$ Percentages of ewes with hypo-, normo-, and hyperglycemic glucose concentrations $(\mathrm{mg} / \mathrm{dL})$.

${ }^{4} \mathrm{All}=$ all farms in total. 


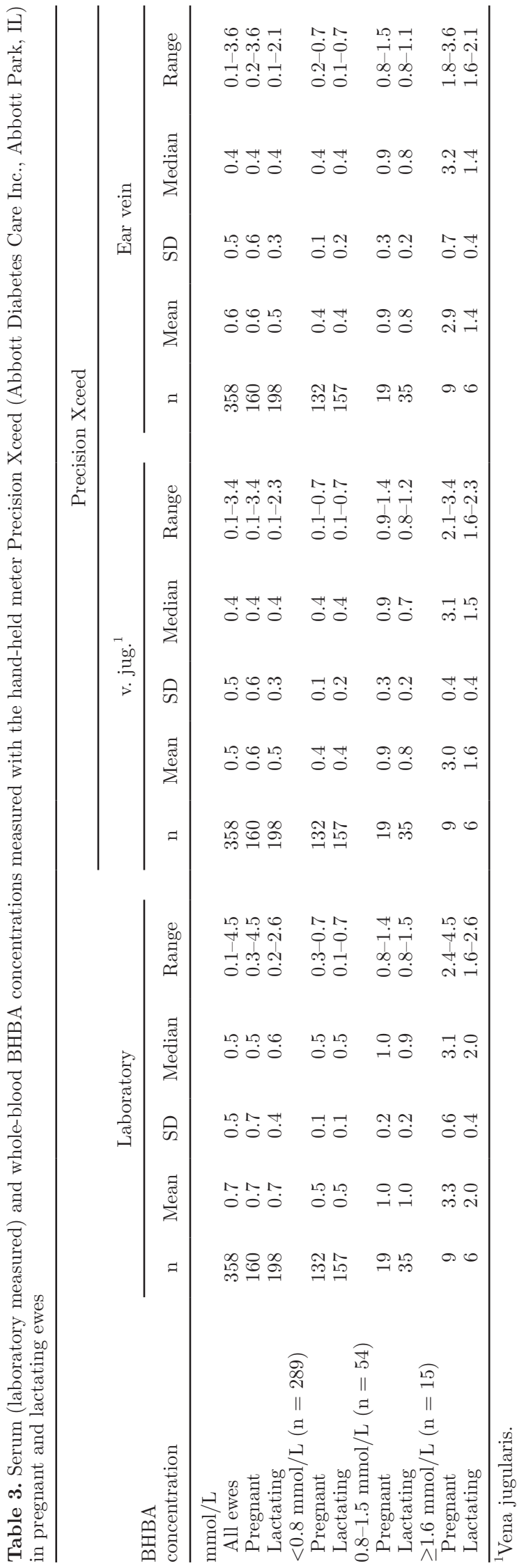

1); for samples obtained from the v. jug., the mean difference between CCPU and PX measurements was $0.15 \mathrm{mmol} / \mathrm{L}\left(\mathrm{CI}_{95}=-0.17\right.$ to 0.46 ; Figure 2$)$.

Applying already established BHBA thresholds of $0.8 \mathrm{mmol} / \mathrm{L}$ and $1.6 \mathrm{mmol} / \mathrm{L}$, either for moderate or severe hyperketonemia, the results of the corresponding thresholds for the device determined by ROC analysis are presented in Table 4. This resulted in optimized thresholds of $0.7 \mathrm{mmol} / \mathrm{L}$ for detecting moderate ketosis with the PX for blood sampled either from an ear vein or the v. jug. Based on this threshold, Se and Sp were 0.83 and 0.93 for blood sampled from an ear vein and 0.81 and 0.96 for blood from the v. jug.

For detection of severe hyperketonemia (BHBA concentration $\geq 1.6 \mathrm{mmol} / \mathrm{L}$ ), adjusted thresholds of $1.0 \mathrm{mmol} / \mathrm{L}$ (ear vein) and $1.1 \mathrm{mmol} / \mathrm{L}$ (v. jug.) were determined for samples analyzed with the PX. By application of these thresholds, the hand-held meter demonstrated excellent $\mathrm{Se}\left(\mathrm{Se}_{\text {ear vein }}=1.00 ; \mathrm{Se}_{\mathrm{v} \text {. jug. }}=1.00\right)$ and $\mathrm{Sp}\left(\mathrm{Sp}_{\text {ear vein }}=0.98 ; \mathrm{Sp}_{\mathrm{v} \text {. jug. }}=0.97\right)$, hence leading to high $\mathrm{YI}\left(\mathrm{YI}_{\text {ear vein }}=0.98 ; \mathrm{YI}_{\mathrm{v} \text {. jug. }}=0.97\right)$.

\section{Concentration of Glucose}

Plasma glucose concentrations determined at the laboratory in samples of 358 ewes ranged from 22.0 to $125.0 \mathrm{mg} / \mathrm{dL}$ (mean $66.4 \pm 13.9 \mathrm{mg} / \mathrm{dL}$ ). Ear vein and v. jug. whole-blood glucose concentrations measured with the PX were 21.0 to $98.0 \mathrm{mg} / \mathrm{dL}$ (mean 49.8 $\pm 11.3 \mathrm{mg} / \mathrm{dL}$ ) and 22.0 to $133.0 \mathrm{mg} / \mathrm{dL}$ (mean $58.5 \pm$ $14.7 \mathrm{mg} / \mathrm{dL}$ ), respectively. The percentage of samples with plasma glucose concentrations below $50 \mathrm{mg} / \mathrm{dL}$ (hypoglycemic) was $7.0 \%(\mathrm{n}=26)$. Normoglycemic results were obtained from $42.0 \%(\mathrm{n}=151)$, whereas hyperglycemic concentration $(\geq 64 \mathrm{mg} / \mathrm{dL})$ were found in $51.0 \%(\mathrm{n}=181)$ of the samples. The mean glucose concentration was significantly lower $(P=0.047)$ in animals classified with severe hyperketonemia (BHBA concentration $\geq 1.6 \mathrm{mmoL} / \mathrm{L}$ ) compared with ewes with BHBA concentrations $<0.8 \mathrm{mmol} / \mathrm{L}$ (Figure 3). Mean glucose concentration was $10.02 \mathrm{mg} / \mathrm{dL}$ lower in severe hyperketonemic animals than in animals with physiological BHBA concentrations. Significant correlations were found between the plasma glucose concentration analyzed at the CCPU and the glucose concentrations in whole blood from an ear vein $(\mathrm{r}=0.47 ; P<0.01)$ and from the v. jug. $(\mathrm{r}=0.68 ; P<0.01)$ measured with the hand-held meter.

The mean deviation in plasma and whole-blood glucose concentration was $17.1 \mathrm{mg} / \mathrm{dL} \quad\left(\mathrm{CI}_{95}=\right.$ -8.6 to 42.8) for samples from an ear vein and 8.4 $\mathrm{mg} / \mathrm{dL}\left(\mathrm{CI}_{95}=-13.9\right.$ to 30.7$)$ for samples from the v. jug., respectively. Figure 4 and 5 show the BlandAltman plots of the differences between the glucose 


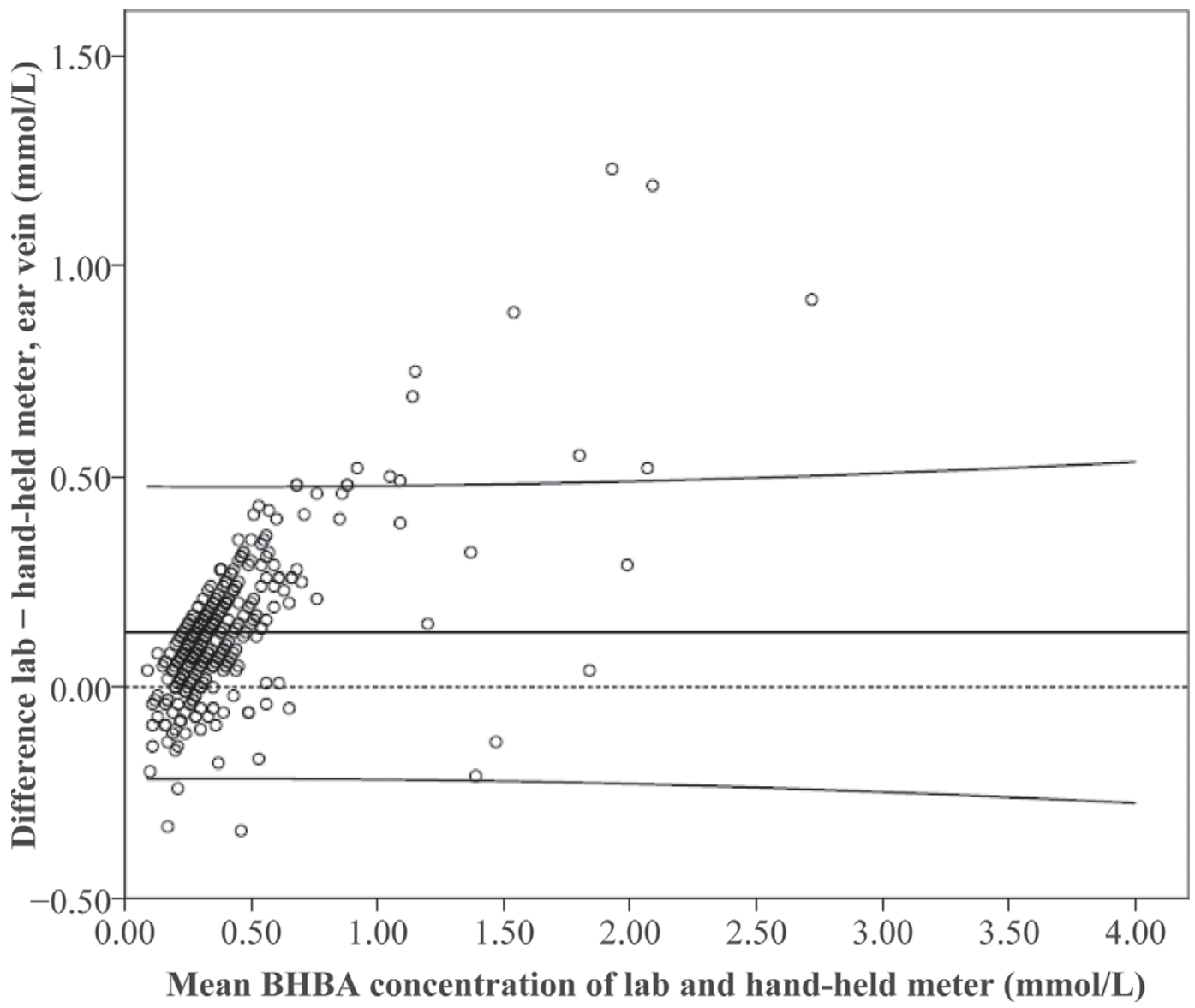

Figure 1. Bland-Altman plot of differences between BHBA concentrations measured in serum at the laboratory and measured in whole blood sampled from an ear vein with the hand-held meter Precision Xceed (Abbott Diabetes Care Inc., Abbott Park, IL) against their mean concentrations. The solid line in the middle represents the mean; the upper and lower solid lines represent the mean \pm 2 SD.

concentrations determined at the CCPU and with the PX.

Furthermore, thresholds were evaluated by ROC analysis for whole-blood glucose concentrations determined with the PX device (Table 5). For samples taken from the v. jug., a threshold of $\leq 49 \mathrm{mg} / \mathrm{dL}$ indicated a hypoglycemic status of the ewes, with Se of 0.73 and Sp of 0.77. Hyperglycemia was detected at thresholds of $>59 \mathrm{mg} / \mathrm{dL}$, with Se of 0.61 and $\mathrm{Sp}$ of 0.79 . For samples obtained from an ear vein, thresholds of $\leq 43$ $\mathrm{mg} / \mathrm{dL}$ were determined to diagnose hypoglycemia (Se $=0.72 ; \mathrm{Sp}=0.73)$ and $>48 \mathrm{mg} / \mathrm{dL}$ to detect animals with hyperglycemia $(\mathrm{Se}=0.68 ; \mathrm{Sp}=0.65)$.

\section{DISCUSSION}

Hand-held devices are widely used in dairy farms as additional diagnostic tests for monitoring of ketosis. Several studies presented excellent Se and Sp for determination of BHBA using these electronic devices in cattle (Oetzel and McGuirk, 2007; Iwersen et al., 2009; Voyvoda and Erdogan, 2010).

Similar to a previous study (Panousis et al. 2012) on the use of the hand-held meter for on-site monitoring of ketosis in sheep, we found excellent positive correlations for BHBA concentrations measured in the laboratory and with the PX. Panousis et al. (2012) reported a strong positive correlation $(\mathrm{r}=0.99)$ for BHBA concentrations determined with the PX and in the laboratory. In our study, the correlation between BHBA concentration in blood from the v. jug. analyzed at the CCPU and with the hand-held meter was 0.96 .

To our knowledge, this is the first study evaluating BHBA and glucose measurement of blood obtained from an ear vein with an electronic hand-held meter in sheep, as an alternative minimally invasive technique. Using the hand-held device, only a single blood drop is necessary for analysis of BHBA or glucose concentrations. After restraining the head of the animal, this blood drop was easily and quickly obtained in most 
Table 4. Receiver operating characteristic (ROC) analysis for the hand-held meter Precision Xceed (Abbott Diabetes Care Inc., Abbott Park, IL) from whole blood of an ear vein and the vena jugularis (v. jug.) in sheep $(\mathrm{n}=358)$

\begin{tabular}{lccccccc}
\hline $\begin{array}{l}\text { Threshold BHBA } \\
\text { concentration }^{1}\end{array}$ & $\begin{array}{c}\text { Opt. cutoff }^{2} \\
(\mathrm{mmol} / \mathrm{L})\end{array}$ & $\mathrm{Se}^{3}(\%)$ & $\mathrm{Se} \mathrm{CI}_{95}{ }^{4}$ & $\mathrm{Sp}^{5}(\%)$ & $\mathrm{Sp} \mathrm{CI}_{95}$ & $\mathrm{AUC}^{6}$ & $\mathrm{YI}^{7}$ \\
\hline $\begin{array}{l}0.8 \mathrm{mmol} / \mathrm{L} \\
\text { Ear vein }\end{array}$ & 0.7 & 82.6 & $71.6-90.7$ & 92.7 & $89.1-95.4$ & 0.94 & 0.78 \\
$\quad$ v. jug. & 0.7 & 81.2 & $69.9-89.6$ & 95.8 & $92.9-97.8$ & 0.96 & 0.80 \\
$\begin{array}{l}1.6 \text { mmol/L } \\
\text { Ear vein }\end{array}$ & 1.0 & 100 & $78.2-100.0$ & 97.1 & $94.7-98.6$ & 0.99 & 0.97 \\
v. jug. & 1.1 & 100 & $78.2-100.0$ & 98.3 & $96.2-99.4$ & 0.99 & 0.98 \\
\hline
\end{tabular}

${ }^{1}$ Serum BHBA concentration analyzed at the laboratory.

${ }^{2}$ Optimized cutoff value for Precision Xceed device.

${ }^{3}$ Sensitivity (percentage of diseased ewes that tested positive).

${ }^{4} \mathrm{CI}_{95}=95 \%$ CI.

${ }^{5}$ Specificity (percentage of healthy ewes that tested negative).

${ }^{6}$ Area under the ROC curve.

${ }^{7}$ Youden index $(\mathrm{Se}+\mathrm{Sp}-1)$.

cases by venipuncture of an ear vein with a small needle. In most cases no and just in a few cases low defensive reactions of the animals were observed; hence, we recommend this method.
A strong positive correlation was detected between BHBA concentrations measured in whole blood of an ear vein and the laboratory results measured from the v. jug. $(\mathrm{r}=0.94)$. The results of our study indicate that



Figure 2. Bland-Altman plot of differences between BHBA concentrations measured in serum at the laboratory and whole blood sampled from the vena jugularis (v. jug.) with the hand-held meter Precision Xceed (Abbott Diabetes Care Inc., Abbott Park, IL) against their mean concentrations. The solid line in the middle represents the mean; the upper and lower solid lines represent the mean \pm 2 SD. 


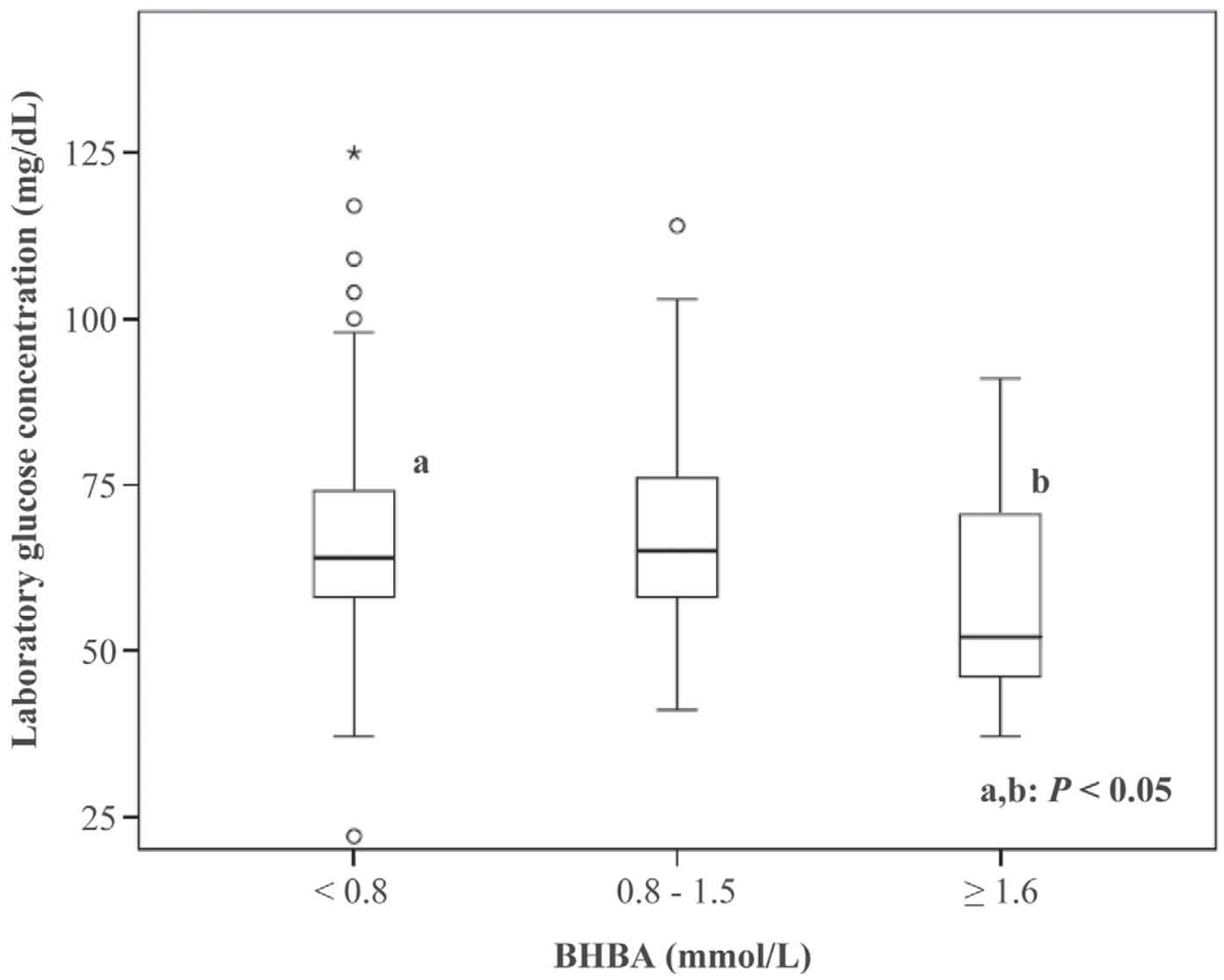

Figure 3. Box plot for glucose concentration within BHBA classes for physiological concentration (BHBA concentration $<0.8$ mmol/L), moderate hyperketonemia (BHBA concentration $0.8-1.5 \mathrm{mmol} / \mathrm{L}$ ), and severe hyperketonemia (BHBA concentration $\geq 1.6 \mathrm{mmol} / \mathrm{L}$ ). The heavy black line inside each box marks the median (50th percentile); lower and upper hinges mark the 25th and 75th percentiles. Whiskers end at the smallest and largest statistical values that are not outliers; outliers and extreme values are designated by $\bigcirc$ and *.

a single blood drop obtained from an ear vein is suitable for detection of BHBA concentration. In total, 15.1\% $(\mathrm{n}=54)$ of all animals were classified as moderately ketotic. In the literature, a higher prevalence has been reported that is related to under- or overconditioning of the ewes (Andrews, 1997; Liamadis and Milis, 2007). Body condition and feeding conditions of the animals, however, were not systematically evaluated in the present study. The prevalence of $4.2 \%(\mathrm{n}=15)$ for ewes with BHBA concentrations above $1.6 \mathrm{mmol} / \mathrm{L}$ and the quantity of animals with symptoms of pregnancy toxemia $(\mathrm{n}=9)$ was low. Further research is required to evaluate the electronic device with more animals suffering from severe ketosis.

The correlations between the plasma glucose concentration measured in the laboratory and the wholeblood glucose concentration were 0.68 (v. jug.) and 0.47 (ear vein), respectively. These correlation coefficients were lower than that reported by Panousis et al. (2012; $\mathrm{r}=0.76 ; P<0.01)$. Whereas the results for glucose concentration obtained from samples from the v. jug. are representative, the concentration resulting from an ear vein should be interpreted carefully, because of the medium significant correlation.

For a detailed evaluation of a diagnostic system, however, it is not always adequate to determine only a correlation between different diagnostic systems (Bland and Altman, 1986). The study by Panousis et al. (2012) evaluated correlations and test characteristics for the PX meter. In our study, the Bland-Altman plot for difference between CCPU and hand-held meter results against their means showed that the PX underestimates the serum BHBA and plasma glucose concentrations. The whole-blood BHBA concentrations were 0.13 (ear vein) and 0.15 (v. jug.) mmol/L lower than the mean serum values determined at the CCPU. Monitoring ketosis in dairy cows, the Bland Altman plot reported by Iwersen et al. (2009) demonstrated an excellent agreement between measurement with an electronic device and the results from a laboratory. In our study, the mean deviation and $95 \%$ confidence intervals were almost equal in the plot for the ear vein and v. jug., 




Figure 4. Bland-Altman plot of differences between glucose concentrations measured in plasma at the laboratory and whole blood sampled from an ear vein and measured with the hand-held meter Precision Xceed (Abbott Diabetes Care Inc., Abbott Park, IL) against their mean concentrations. The solid line in the middle represents the mean; the upper and lower solid lines represent the mean \pm 2 SD.

indicating that BHBA testing could be performed with blood from an ear vein and v. jug. interchangeably. The deviation in Bland-Altman plot for glucose concentration was $17.1 \mathrm{mg} / \mathrm{dL}$ for the ear vein and $8.4 \mathrm{mg} / \mathrm{dL}$ for the v. jug. It is stated that the serum and plasma glucose concentration is greater than the concentration evaluated in whole blood (Kuwa et al., 2001; Kraft et al., 2005). Kuwa et al. (2001) reported a significant difference between glucose concentrations determined in venous whole blood and venous plasma. Glucose concentrations in plasma are $13.2 \%$ greater than concentrations evaluated from venous whole blood (Kuwa et al., 2001). This could be a major reason for the observed bias between the concentrations measured with the hand-held device and in the CCPU. Considering the results of Kuwa et al. (2001), the whole-blood BHBA levels were converted into plasma glucose levels $(+13 \%)$. As result of this conversion, the bias of the concentration determined from the ear vein was reduced from 17.1 to $10.6 \mathrm{mg} / \mathrm{dL}\left(\mathrm{CI}_{95}=9.2\right.$ to 12.1$)$ and from 8.4 to $0.8 \mathrm{mg} / \mathrm{dL}$ for samples from the v. jug. $\left(\mathrm{CI}_{95}=-0.51\right.$ to 2.1$)$, respectively. Additionally, several studies presented an influence of anticoagulants on the glucose concentration (Christopher and O'Neill, 2000; Morris et al., 2002; Waring et al., 2007). Besides this, storage and temperature conditions are also very important and can also influence the concentration of the metabolites BHBA and glucose (Zhang et al., 1998; Morris et al., 2002).

Because the PX measurements showed a good correlation (BHBA) with the CCPU measurements, but lower absolute values, an adjustment of the thresholds was necessary for the correct interpretation of values displayed by the device (Figure 1 and 2). Therefore, ROC analyses were performed to determine optimized thresholds for the device to detect cases of moderate and severe hyperketonemia with high accuracy. Especially for diagnosis of ewes suffering from severe hyperketonemia (BHBA concentration $\geq 1.6 \mathrm{mmol} / \mathrm{L}$ ), it is recommended to use optimal cutoffs of 1.0 and $1.1 \mathrm{mmol} / \mathrm{L}$ for measurements of BHBA in whole blood of an ear vein and v. jug. According to these thresholds, the PX Se and Sp both were 1.00. Also, the study by Panousis et al. (2012) reported that the PX was 
Table 5. Receiver operating characteristic (ROC) analysis for the hand-held meter Precision Xceed (Abbott Diabetes Care Inc., Abbott Park, IL) from whole blood of an ear vein and the vena jugularis (v. jug.) in sheep $(\mathrm{n}=358)$

\begin{tabular}{lccccccc}
\hline $\begin{array}{l}\text { Threshold glucose } \\
\text { concentration }^{1}\end{array}$ & $\begin{array}{c}\text { Opt. cutoff } \\
(\mathrm{mg} / \mathrm{dL})\end{array}$ & $\mathrm{Se}^{3}(\%)$ & $\mathrm{Se} \mathrm{CI}_{95}{ }^{4}$ & $\mathrm{Sp}^{5}(\%)$ & $\mathrm{Sp} \mathrm{CI}_{95}$ & $\mathrm{AUC}^{6}$ & $\mathrm{YI}^{7}$ \\
\hline $50 \mathrm{mg} / \mathrm{dL}$ & & & & & & & \\
$\quad$ Ear vein & $\leq 43$ & 72.3 & $49.8-89.3$ & 73.1 & $67.9-77.8$ & 0.76 & 0.46 \\
$\quad$ v. jug. & $\leq 49$ & 72.7 & $49.8-89.3$ & 77.4 & $72.4-81.8$ & 0.78 & 0.50 \\
$\quad \begin{array}{l}\text { mg/dL } \\
\text { Ear vein }\end{array}$ & $>48$ & 68.3 & $61.0-75.1$ & 65.1 & $57.4-72.2$ & 0.70 & 0.33 \\
v. jug. & $>59$ & 61.1 & $53.6-68.3$ & 79.9 & $73.0-85.6$ & 0.77 & 0.41 \\
\hline
\end{tabular}

${ }^{1}$ Plasma glucose concentration analyzed at the laboratory.

${ }^{2}$ Optimized cutoff value for the Precision Xceed device for measurement of hypo-, normo-, and hyperglycemia.

${ }^{3}$ Sensitivity (percentage of diseased ewes that tested positive).

${ }^{4} \mathrm{CI}_{95}=95 \%$ CI.

${ }^{5}$ Specificity (percentage of healthy ewes that tested negative).

${ }^{6}$ Area under the ROC curve.

${ }^{7}$ Youden index $(\mathrm{Se}+\mathrm{Sp}-1)$.

highly sensitive (0.98) and specific (0.98), according to a BHBA threshold of $0.8 \mathrm{mmol} / \mathrm{L}$.

Animals suffering from severe hyperketonemia (BHBA concentration $\geq 1.6 \mathrm{mmol} / \mathrm{L}$ ) were found to have lowered glucose concentrations by $-10.02 \mathrm{mg} / \mathrm{dL}$ compared with healthy animals. Several studies argued that hypoglycemia is the major factor leading to hyperketonemia (Henze et al., 1998; Rook, 2000; Sargison,

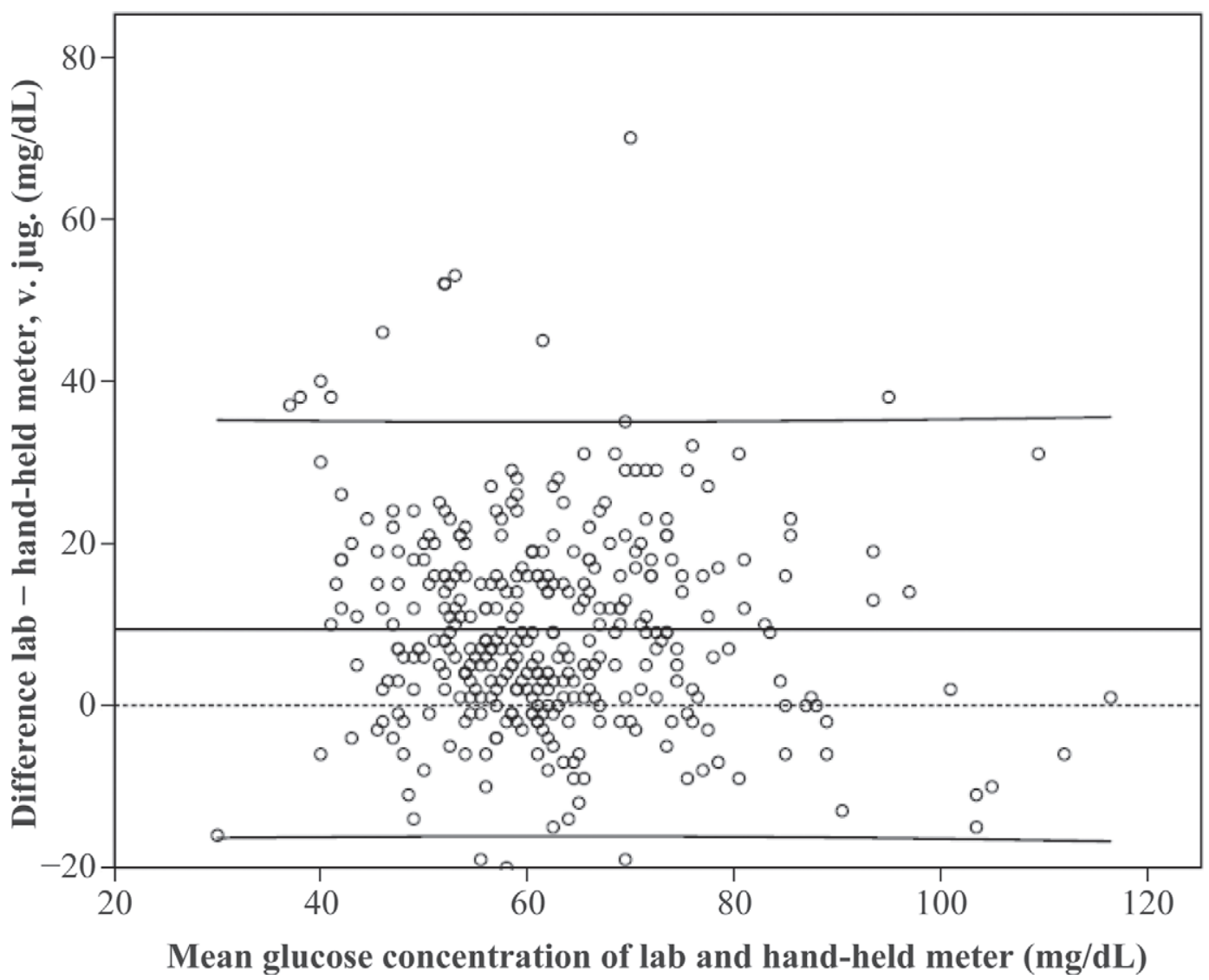

Figure 5. Bland-Altman plot of differences between glucose concentrations measured in plasma at the laboratory and whole blood sampled from the vena jugularis (v. jug.) and measured with the hand-held meter Precision Xceed (Abbott Diabetes Care Inc., Abbott Park, IL) against their mean concentrations. The solid line in the middle represents the mean; the upper and lower solid lines represent the mean \pm 2 SD. 
2007; Mavrogianni and Brozos, 2008). Schlumbohm and Harmeyer (2004) reported that severely elevated BHBA concentration leads to a significant decrease of endogenous glucose production, but has no effect on glucose utilization. In ewes carrying twins during late pregnancy, hyperketonemia in combination with hypoglycemia contributes to a significant reduction of available glucose. Several studies reported a higher risk for animals carrying more than 1 lamb to develop ketosis (Frrat and Özpınar, 2002; Schlumbohm and Harmeyer, 2008; Moallem et al., 2012). Panousis et al. (2012) reported a significant greater BHBA concentration in dry than in lactating sheep. No differences between lactating and pregnant ewes in terms of BHBA and glucose concentrations were found in our study, but further research is needed with a greater number of ewes of different breeds in late pregnancy and early lactation.

The primary cause of hypoglycemia in the last weeks before parturition of ewes pregnant with twins is an increased susceptibility to a stress-related reduction in the glucose production rate (Schlumbohm and Harmeyer, 2008). A reduced ability of the ewes to utilize BHBA in late pregnancy and reduced hepatic metabolic efficiency are supposed to be the main causes for hyperketonemia (Andrews, 1997; Harmeyer and Schlumbohm, 2006).

In our study, $51 \%$ of all ewes presented glucose concentrations equal or above $64 \mathrm{mg} / \mathrm{dL}$. We were not able to determine the primary cause for hyperglycemia in these sheep. Several studies in human medicine reported that stress leads to hyperglycemia (Finney et al., 2003; Fahy et al., 2009). All animals were fixed manually before collecting blood samples from the v. jug. and an ear vein. All handlings with the animals were conducted as quickly as possible, but we cannot exclude that restraining the ewes was stressful and, as a consequence, this was the main cause of the hyperglycemic concentrations. Another explanation could be that the reference values for glucose should be reevaluated, as the breeding regimens might have affected glucose metabolism. Furthermore, analytical methods have been refined so that this issue should be further investigated.

Several studies considered economic aspects related to the diagnosis, treatments, and outcome of hyperketonemia (Oetzel and McGuirk, 2007; Voyvoda and Erdogan, 2010; Panousis et al., 2012). It can be hypothesized that not only can costs for diagnoses be reduced by use of the hand-held meter compared with sending samples to a laboratory, but also the success of a treatment can be improved with a quick and on-site diagnosis. This, however, should be evaluated in further studies. Furthermore, the option of taking a blood sample from an ear vein to determine BHBA could be beneficial for routine monitoring of ewes at higher risk for pregnancy toxemia.

\section{CONCLUSIONS}

The hand-held PX device showed excellent test characteristics to detect moderate and severe hyperketonemia. Furthermore, a single drop of blood obtained from an ear vein is suitable for detecting hyperketonemia in sheep. Determination of BHBA concentration presented better test characteristics than measurements of glucose concentrations in whole blood. Especially for determination of glucose from the blood of an ear vein, test characteristics (Sp, Se, and YI) were low. Hence, glucose concentrations should be analyzed from blood obtained from the v. jug. When using the PX to determine BHBA or glucose concentrations in whole blood, the thresholds should be adjusted.

\section{ACKNOWLEDGMENTS}

We acknowledge our partner LFZ RaumbergGumpenstein (Styria, Austria) and especially all the farmers who provided their animals for this study.

\section{REFERENCES}

Andrews, A. 1997. Pregnancy toxaemia in the ewe. In Pract. 19:306312 .

Bickhardt, K. 2009. Stoffwechsel- und Mangelkrankheiten. Pages 105152 in Lehrbuch der Schafkrankheiten. 4th ed. M. Ganter ed., Parey, Stuttgart, Germany.

Bland, J. M., and D. G. Altman. 1986. Statistical methods for assessing agreement between two methods of clinical measurement. Lancet 1:307-310.

Bostedt, H., and K. Dedie. 1996. Stoffwechsel- und Mangelkrankheiten. Pages 133-173 in Schaf- und Ziegenkrankheiten. 2nd ed. K. Loeffler and D. Strauch ed. Eugen Ulmer GmbH \& Co., Stuttgart, Germany.

Brozos, C., V. S. Mavrogianni, and G. C. Fthenakis. 2011. Treatment and control of peri-parturient metabolic diseases: Pregnancy toxemia, hypocalcemia, hypomagnesemia. Vet. Clin. North Am. Food Anim. Pract. 27:105-113.

Christian, J. A., and D. G. Pugh. 2012. Reference intervals and conversions. Pages 596-600 in Sheep and Goat Medicine. 2nd ed. D. G. Pugh and A. N. Baird ed. Elsevier Inc., Maryland Heights, MO.

Christopher, M. M., and S. O'Neill. 2000. Effect of specimen collection and storage on blood glucose and lactate concentrations in healthy, hyperthyroid and diabetic cats. Vet. Clin. Pathol. 29:22-28.

Fahy, B. G., A. M. Sheehy, and D. B. Coursin. 2009. Glucose control in the intensive care unit. Crit. Care Med. 37:1769-1776.

Finney, S. J., C. Zekveld, A. Elia, and T. W. Evans. 2003. Glucose control and mortality in critically ill patients. JAMA 290:2041-2047.

Fırat, A., and A. Özpınar. 2002. Metabolic profile of pre-pregnancy, pregnancy and early lactation in multiple lambing Sakız ewes. 1. Changes in plasma glucose, 3-hydroxybutyrate and cortisol levels. Ann. Nutr. Metab. 46:57-61.

Fluss, R., D. Faraggi, and B. Reiser. 2005. Estimation of the Youden index and its associated cutoff point. Biom. J. 47:458-472.

Harmeyer, J., and C. Schlumbohm. 2006. Pregnancy impairs ketone body disposal in late gestating ewes: Implications for onset of pregnancy toxemia. Res. Vet. Sci. 81:254-264. 
Henze, P., K. Bickhardt, H. Fuhrmann, and H. P. Sallmann. 1998. Spontaneous pregnancy toxemia (ketosis) in sheep and the role of insulin. Zentralbl. Veterinärmed. A 45:255-266.

Iwersen, M., U. Falkenberg, R. Voigtsberger, D. Forderung, and W. Heuwieser. 2009. Evaluation of an electronic cowside test to detect moderate ketosis in dairy cows. J. Dairy Sci. 92:2618-2624.

Kraft, W., M. Fürll, H. Bostedt, and K. Heinritzi. 2005. Klinische Endokrinologie. Untersuchung des Blutes. Pages 297-321 in Klinische Labordiagnostik in der Tiermedizin. 6th ed. W. Kraft and U. M. Dürr. ed., Schattauer GmbH, Stuttgart, Germany.

Kuwa, K., T. Nakayama, T. Hoshino, and M. Tominaga. 2001. Relationships of glucose concentrations in capillary whole blood, venous whole blood and venous plasma. Clin. Chim. Acta 307:187-192.

Liamadis, D., and C. Milis. 2007. Significance of quality of truly digestible protein on performance of ewes at late pregnancy and early lactation. Small Rumin. Res. 71:67-74.

Mavrogianni, V. S., and C. Brozos. 2008. Reflections on the causes and the diagnosis of peri-parturient losses of ewes. Small Rumin. Res. 76:77-82.

Moallem, U., A. Rozov, E. Gootwine, and H. Honig. 2012. Plasma concentrations of key metabolites and insulin in late-pregnant ewes carrying 1 to 5 fetuses. J. Anim. Sci. 90:318-324.

Morris, J. D., J. M. Fernandez, A. M. Chapa, L. R. Gentry, K. E. Thorn, and T. M. Weick. 2002. Effects of sample handling, processing, storage, and hemolysis on measurements of key energy metabolites in ovine blood. Small Rumin. Res. 43:157-166.

Oetzel, G. R., and S. M. McGuirk. 2007. Fact sheet - Cowside blood BHBA testing with a hand-held "ketometer". Version 4, 3/5/09. School of Veterinary Medicine, University of Wisconsin-Madison. Accessed May 16, 2013. http://www.vetmed.wisc.edu/dms/fapm/ fapmtools/tci/BHBA-Testing-Update-090305.pdf.
Panousis, N., C. Brozos, I. Karagiannis, N. D. Giadinis, S. Lafi, and M. Kritsepi-Konstantinou. 2012. Evaluation of precision Xceed ${ }^{\circledR}$ meter for on-site monitoring of blood $\beta$-hydroxybutyric acid and glucose concentrations in dairy sheep. Res. Vet. Sci. 93:435-439.

Rook, J. S. 2000. Pregnancy toxemia of ewes, does, and beef cows. Vet. Clin. North Am. Food Anim. Pract. 16:293-317,vi-vii.

Sargison, N. D. 2007. Pregnancy toxemia. Pages 359-363 in Diseases of Sheep. 4th ed. I. D. Aitken ed. Blackwell Publishing Ltd., Oxford, UK.

Schlumbohm, C., and J. Harmeyer. 2004. Hyperketonemia impairs glucose metabolism in pregnant and nonpregnant ewes. J. Dairy Sci. 87:350-358.

Schlumbohm, C., and J. Harmeyer. 2008. Twin-pregnancy increases susceptibility of ewes to hypoglycaemic stress and pregnancy toxaemia. Res. Vet. Sci. 84:286-299.

Schwendenwein, I. 2009. Probenahme, Laboruntersuchungen und invasive diagnostische Maßnahmen. Untersuchung des Blutes. Pages 432-461 in Klinische Propädeutik der Haus- und Heimtiere. 7th ed. W. Baumgartner ed. Parey, Stuttgart, Germany.

Voyvoda, H. and H. Erdogan. 2010. Use of a hand-held meter for detecting moderate ketosis in dairy cows. Res. Vet. Sci. 89:344-351.

Waring. W. S., L. E. Evans, and C. T. Kirkpatrick. 2007. Glycolysis inhibitors negatively bias blood glucose measurements: Potential impact on the reported prevalence of diabetes mellitus. J. Clin. Pathol. 60:820-823.

Zhang, D. J., R. K. Elswick, W. G. Miller, and J. L. Bailey. 1998. Effect of serum-clot contact time on clinical chemistry laboratory results. Clin. Chem. 44:1325-1333. 